\title{
Flood Source
}

National Cancer Institute

\section{Source}

National Cancer Institute. Flood Source. NCI Thesaurus. Code C94898.

A uniform distribution of a radioisotope in a large container which can be placed in an imaging device for purposes of quality control checking. 